\title{
Sociodemographic Variations in the Sense of Control by Domain: Findings From the MacArthur Studies of Midlife
}

\author{
Margie E. Lachman and Suzanne L. Weaver \\ Brandeis University
}

\begin{abstract}
Past research has focused on general control beliefs with little attention to whether control beliefs vary across domains. Also, most age-comparative studies have examined control beliefs in younger and older adults but not in middle-aged adults. This study examined assessments of control in 7 domains for a large probability sample of adults $25-75$ years in age. Results revealed differential age patterns across domains: Increases in control by age were found for control over work, finances, and marriage, whereas decreases were found for control over relationship with children and sex life. Control beliefs in some domains also varied by gender and education, but the age patterns were consistent across these sociodemographic groups. Domain-specific control beliefs were significantly related to a variety of domain-relevant experiences and outcomes.
\end{abstract}

The sense of control has been identified repeatedly as an important ingredient for successful aging (Baltes \& Baltes, 1986; Brändtstadter \& Renner, 1990; Brim, 1992; Rodin, 1986; Rowe \& Kahn, 1987; Schulz, Heckhausen, \& Locher, 1991). In the context of aging, control is often associated with loss: losing control over bodily functions or over one's mind. However, there is some evidence that the sense of control varies across domains, with some areas showing a decreased sense of control (e.g., mental functioning) and others (e.g., social relations) showing either an increase or stability (Lachman, 1986, 1991).

In past work, the focus has been primarily on measures of global or general control using items from the Rotter Locus of Control scale or similar instruments (Lachman, 1986). Although there have been some studies and instruments focused on specific domains such as health (Wallston \& Wallston, 1981) or intellectual functioning (Lachman, 1986; Lachman, Bandura, Weaver, \& Elliott, 1995), the range of domains has been limited. Consideration of multiple domains is particularly useful for a developmental perspective because trajectories of age differences have been found to differ by domain (Lachman, 1991). Moreover, in past work age differences were usually less pronounced for generalized measures than for specific domains (Lachman, 1991). Generalized control measures represent a composite of different areas of life, which on balance may show little variation with age.

In a longitudinal investigation of a related construct, selfefficacy beliefs, McAvay, Seeman, and Rodin (1996) found changes over a 3-year period varied by domain. The measure-

Margie E. Lachman and Suzanne L. Weaver, Department of Psychology, Brandeis University.

This research was supported by a grant from the John D. and Catherine T. MacArthur Foundation Research Network on Successful Midlife Development, Orville Gilbert Brim, Chair.

Correspondence regarding this article should be addressed to Margie E. Lachman, Department of Psychology, Brandeis University, Waltham, Massachusetts 02254. Electronic mail may be sent to lachman@ binah.cc.brandeis.edu. ment approach used by McAvay et al. (1996) is similar to the assessment of domain-specific control in our study. McAvay et al. selected domains (e.g., transportation, safety, health) that were specifically relevant for their older adult sample (all over age 62). They found their participants overall were most likely to experience declines over time in the financial, safety, and productivity domains. However, age, sex, and education were not related to patterns of change, perhaps because age and education had a somewhat restricted in range in their sample. The focus of our study was on variations in the degree to which one feels in control of what happens in key areas of life relevant for a wider range of adults in terms of age and education.

Most age-comparative studies of control beliefs have included younger and older adults without attention to the middle years of the life span. Moreover, samples have often been small and non-representative. There was some indication from past work (Lachman, Lewkowicz, Marcus, \& Peng, 1994; Mirowsky, 1995; Neugarten, 1968; Wolinsky \& Stump, 1996) that perceived control over life is higher in middle age than in younger and older adulthood. This may be because those in middle age are at the peak of their careers in many domains of life such as the work and financial realms. Those in midlife are often in more powerful and responsible positions on the job and in the family when compared to those who are younger or older (Lachman \& James, 1997). However, there has been no attention to whether the sense of control in midlife would vary across different life domains. There is also evidence from past work that education plays a role in control beliefs such that much of the variation by age can be attributed to differences in education (Mirowsky, 1995; Wolinsky \& Stump, 1996). Higher education can be expected to foster a greater sense of control because it affords greater opportunities for advancement and leadership (Gurin \& Brim, 1984). Interactions between age and education however have not been thoroughly examined in past research. Because our study has a wide range in years of education for all age groups, it is possible to examine whether age patterns are consistent or vary across educational levels.

In our study we examined control beliefs for seven key do- 
mains in adults ages 25 to 75 using a large probability sample of the U.S. population. For comparative purposes, we included three measures of generalized control beliefs to determine if sociodemographic differences would be similar to those found for domain-specific measures. We examined the relationship between domain-specific and generalized control measures as well as their relationships with domain-relevant experiences and outcomes in the seven representative domains for purposes of validity. We asked the following questions: (a) Do control beliefs vary across domains? (b) Are there differences in generalized and domain-specific control beliefs by age, gender, or educational level? (c) Do patterns of age differences in control beliefs vary by gender or educational level? (d) Are domainspecific control beliefs related to experiences and outcomes relevant to the domain?

\section{Method}

\section{Participants}

A national probability sample of households with at least one telephone was selected using random digit dialing for the Midlife in the United States Survey (MIDUS) conducted by the John D. and Catherine T. MacArthur Foundation Network on Successful Midlife Development. A sample of 3,485 noninstitutionalized adults was interviewed for $20-$ $30 \mathrm{~min}$ by telephone ( $70 \%$ response rate) and then received a twobooklet self-administered questionnaire in the mail. Our study includes the 3,032 respondents ( $87 \%$ response rate) who returned the questionnaire.'

The age of the participants ranged from 25 to 75 years $(M=47.06$ years, $S D=13.11$ ). Men comprised $49 \%$ of the sample. The majority of the sample participants were Caucasian $(89 \%)$, and over half were married $(64 \%)$. Of the total sample, $10 \%$ had less than a high school diploma, $29 \%$ had completed high school or a general equivalency diploma (G.E.D.), $31 \%$ had completed some college, and $30 \%$ had attained a baccalaureate or advanced degree.

\section{Measures}

Control domains. Perceived control in 7 domains (health, work, finances, contribution to the welfare and well-being of other people, relationship with your children, marriage or close relationship, and sexual aspect of your life) was assessed using an 11-point rating scale for each domain $(0=$ no control at all, $10=$ very much control $)$. These 7 domains were selected by consensus in an interdisciplinary research group specializing in midlife development to represent areas of life considered relevant throughout adulthood. The items cover the realms of work, family, social relations, and physical functioning. The wording of the item was as follows: Using a $0-10$ scale where 0 means no control at all and 10 means very much control, how would you rate the amount of control you have over your these days?

Generalized control. Three measures of generalized control were included. One measure used a single-item rating scale in which respondents indicated how much control they had over their life overall $(0=$ no control, $10=$ very much control). The wording of this item was parallel to the wording used for the 7 domains. In addition, generalized control was operationalized by two dimensions: personal mastery and perceived constraints (Lachman \& Weaver, 1998). Personal mastery refers to one's sense of efficacy or effectiveness in carrying out goals. Perceived constraints indicate to what extent one believes there are obstacles or factors beyond one's control that interfere with reaching goals. The mastery scale (Cronbach's $\alpha=.70$ ) included four items (e.g., whether or not I am able to get what I want is in my own hands) whereas the constraints scale (Cronbach's $\alpha=.86$ ) included eight items (e.g., I have little control over the things that happen to me). Both scales included items from Pearlin and Schooler's (1978) mastery scale, and several new items developed to measure these constructs (see Lachman \& Weaver, 1998). These dimensions are consistent with Skinner's (1996) two-fold conceptualization of control as comprised of competence and contingency. Respondents indicated on a 7-point scale the extent to which they agreed with each of the items $(1=$ strongly agree, 7 = strongly disagree $)$. The mean of the reverse-scored items was computed for respondents who had valid items for at least half of the items on each scale. Higher scores reflect greater mastery or greater perceived constraints.

Health domain measures. Seven measures of physical health were obtained. The following two items assessed control over one's health: "Keeping healthy depends on things that I can do" and "When I am sick, getting better is in the doctor's hands." These items were measured on a 7-point scale ( $1=$ strongly agree, $7=$ strongly disagree $)$ and were reverse scored so that higher values indicate stronger endorsement of the statement.

Two additional items assessed respondents' perceived risk of having a heart attack and perceived risk of getting cancer relative to other samegender individuals of their age $(1=$ higher, $2=$ lower, $3=$ about the same). If respondents indicated that their risk was higher than others, they were then asked to say whether their risk was a lot higher, somewhat higher, or only a little higher.

If respondents indicated that their risk was lower than that of others, they then responded whether their risk was a lot lower, somewhat lower, or only a little lower than others. On the basis of these responses, two continuous scales, ranging from 0 to 6 were computed $(0=a$ lot lower risk, 6 = a lot higher risk) for risk of having a heart attack and for risk of getting cancer.

Respondents rated whether or not they had experienced or been treated for 28 health problems in the past 12 months (e.g., asthma, thyroid disease, migraine headaches, ulcer, hay fever, cancer, stroke). A total score was computed on the basis of the number of chronic health problems respondents endorsed. The scores could range from 0 to 28 , with higher scores reflecting a greater number of chronic health problems.

Respondents rated how often they experienced each of 9 physical symptoms during the past 30 days (e.g., lower backaches, trouble getting to sleep or staying asleep, sweating a lot $)$ on a 6-point scale $(1=$ almost everyday, $6=$ not at all $)$. Items were recoded and summed such that scores could range from 0 to 45 . Higher scores reflect more frequent acute health symptoms.

Respondents rated on a 4-point scule ( $1=a$ lot, $4=$ not at all $)$ how much their health limited them in doing each of nine activities (e.g., lifting or carrying groceries, bending, kneeling, or stooping, walking more than a mile). Items were recoded to a 0 to 3 -point scale $(0=$ not at all, $3=a$ lot ) and summed so that higher scores indicate more physical limitations. The possible range of scores was from 0 to 27 .

Work domain measures. Six constructs assessed the conditions of the work environment. These constructs were based on research from the Quality of Employment Surveys developed for the U.S. Department of Labor by the University of Michigan Survey Research Center (Schwartz, Pieper, \& Karasek, 1988; Shannon, 1994). One of these constructs, likelihood of keeping one's job, was operationalized by a single-item rating scale: "If you wanted to stay in your present job, what are the chances that you could keep it for the next two years?"

\footnotetext{
' Compared to the Current Population Survey data, our sample was positively biased in terms of social class. Our sample underrepresented minorities, and those with low income and education. This is likely due to the methods used (i.e. telephone surveys and lengthy self-report questionnaires).
} 
( 1 = excellent, $5=$ poor $)$. This item was reverse scored so that higher values indicate greater likelihood of keeping one's job.

In addition, five scales were derived on the basis of a principle axis factor analysis using varimax rotation of 19 additional items. These items were measured on a 5 -point scale $(1=$ all the time, $5=$ never $)$. Items were reverse scored and scale scores were computed by finding the mean of the items for respondents who had valid values on at least half of the items for the scale. Higher scores indicate greater endorsement of the construct. The skill discretion scale ( 3 items, Cronbach's $\alpha=$ .68 ) assesses the kinds of tasks the job requires (e.g., How often do you learn new things at work?), the decision authority scale ( 6 items, $\alpha$ $=.85$ ) measures how much responsibility the respondent has in making decisions about tasks (e.g., How often do you have a choice in deciding how you do your tasks at work?), the demands scale ( 5 items, $\alpha=$ .74) refers to the extent to which demands are placed on the respondent (e.g., How often do different people or groups at work demand things from you that you think are hard to combine?), the coworker support scale ( 2 items, $\alpha=.74$ ) refers to how friendly and concerned coworkers are toward the respondent (e.g., How often do you get help and support from your coworkers?), and the supervisor support scale ( 3 items, $\alpha=$ .87) measures the responsiveness of the supervisors (e.g., How often do you get help and support from your immediate supervisor?).

Finances domain measures. Three constructs were assessed in the finances domain. Respondents indicated on a 3-point scale $(1=$ more money than you need, $3=$ not enough money) whether they have enough money to meet their needs, "In general, would you say you (and your family living with you) have more money than you need, just enough for your needs, or not enough to meet your needs?"' Respondents also rated how difficult it is for them (and their family) to pay their monthly bills ( $1=$ very difficult, $4=$ not at all difficult $)$. This item was recoded such that higher scores indicate greater difficulty.

Total household income from all sources (personal earnings, spouse's earnings, pensions, interest income, and so on) was also computed to the nearest dollar.

Contributions domain measures. A generativity scale (see McAdams \& St. Albin, 1992) was computed for the contributions to the welfare and well-being of others domain. Respondents indicated on a 4-point scale ( $1=a$ lot, $4=$ not at all $)$ the extent to which each of six statements describes them (e.g., "Others would say that you have made unique contributions to society" and "You have had a good influence on the lives of many people"). Items were reverse scored and the mean of the items was computed for respondents who had valid responses on at least three of the six items. Higher scores indicate greater generativity. Cronbach's $\alpha$ for this scale was .84 .

Relationship with children domain measures. In the domain of relationship with children, two variables were examined: contribution to children's well-being and stress due to children. Contribution to children was operationalized by six items rated on a 4-point scale $(1=$ not at all true, $4=$ extremely true; e.g., "I feel good about the opportunities I have been able to provide for my children" and "As a family, we have not had the resources to do many fun things together with the children"). Negatively worded items were reverse scored, and a scale score was computed on the basis of the mean of the items for respondents who had valid responses on at least three of the six items. Higher values indicate greater contributions to one's children. Cronbach's $\alpha$ for this scale was .69 .

Respondents also rated which of 10 problems any of their children had experienced in the past 12 months (e.g., chronic disease or disability, difficulty finding or keeping a job, legal problems, and so on). A child stress score was computed on the basis of the number of problems their children had experienced $(0=$ no problems, $10=$ all 10 problems $)$.

Marriage relationship domain measures. In the domain of relationship with spouse, two constructs were assessed. A 4-point $(1=$ very likely, $4=$ not likely at all) single item measured the likelihood of separating from one's spouse or partner: "It is always difficult to predict what will happen in a relationship, but realistically, what do you think the chances are that you and your spouse will eventually separate?" This item was reverse scored so that a higher value indicates a greater likelihood of separating.

Respondents also rated which of 10 problems their spouses had experienced in the past 12 months (e.g., chronic disease or disability, difficulty finding or keeping a job, legal problems, and so on). A spouse stress score was computed on the basis of the number of problems their spouse had experienced $(0=$ no problems, $10=$ all 10 problems $)$.

Social support and strain were examined for each respondent's spouse or partner using twelve 4-point $(1=a$ lot, $4=$ not at all $)$ items. Six items measured spouse support (e.g., "How much does he/she understand the way you feel about things?"'), and 6 measured spouse strain (e.g., "How often does he or she let you down when you are counting on him or her?"'). Items were reverse scored, and the mean of the items was computed for each scale, so that higher scores indicate either higher support or higher strain. Cronbach's $\alpha$ was .91 for spouse support and .88 for spouse strain (see Lyons \& Lachman, 1997).

Sex life domain measures. In the domain of sex life, respondents indicated how often they had had sex with someone, on average, over the past 6 months $(1=$ two or more times a week, $6=$ never or not at $a l l)$. This item was recoded so that higher values indicate greater frequency of sex.

\section{Results}

\section{Descriptive Findings}

Table 1 shows the means, standard deviations, and correlations for the control measures for the entire sample. ${ }^{2}$ The means for the domain-control items are listed in ascending order, followed by the three generalized control scales. The ratings for the domain-control items were fairly high (all of the means were more than 6 on the $0-10$ scale). Respondents felt most in control of their marriage and least in control of their finances and sex life. Correlations ranged from .10 to .49 , and all ratings were significantly $(p<.001)$ related. For the mastery and constraints scales, the highest correlations were with each other and with the life overall item and not with the domain-specific items. All correlations with the constraints scale were negative.

\section{Relationships of Control and Domain-Related Variables}

To provide evidence of the validity of the single-item dornaincontrol measures, we examined correlations with variables in each of the 7 domains. Table 2 shows the correlations of these domain-related variables with the generalized control measures (mastery, constraints, life overall). These correlations range from .04 to .37 . For mastery, the correlations with the domainrelevant measures ranged from .04 (work demands scale) to .26 (generativity scale). For constraints, the correlations with the domain-relevant measures ranged from .09 (risk of cancer) to .37 (contribute to child). For life overall the correlations ranged from .08 (child) to .36 (spouse support). These correlations were generally lower in magnitude than those between the do-

\footnotetext{
${ }^{2}$ All results presented are based on unweighted data. Using Current Population Survey data, weights were developed to correct for sampling bias. When the weights were applied, the results of all analyses remained the same.
} 
Table 1

Means, Standard Deviations, and Correlations for Control Dimensions

\begin{tabular}{|c|c|c|c|c|c|c|c|c|c|c|c|c|}
\hline Variable & $M$ & $S D$ & 1 & 2 & 3 & 4 & 5 & 6 & 7 & 8 & 9 & 10 \\
\hline 1. Finances & 6.60 & 2.52 & - & & & & & & & & & \\
\hline 2. Sex & 6.65 & 3.00 & .20 & - & & & & & & & & \\
\hline 3. Contributions & 7.04 & 2.54 & .30 & .15 & - & & & & & & & \\
\hline 4. Work & 7.07 & 2.66 & .35 & .15 & .30 & $\ldots$ & & & & & & \\
\hline 5. Child & 7.59 & 2.48 & .10 & .19 & .15 & .14 & - & & & & & \\
\hline 6. Health & 7.65 & 1.90 & .25 & .21 & .20 & .27 & .15 & $\ldots$ & & & & \\
\hline 7. Marriage & 7.80 & 2.15 & .30 & .39 & .16 & .21 & .21 & .18 & - & & & \\
\hline 8. Life & 7.81 & 1.88 & .49 & .35 & .32 & .42 & .23 & .39 & .45 & - & & \\
\hline 9. Mastery & 5.84 & 1.02 & .27 & .19 & .18 & .24 & .17 & .28 & .19 & .37 & - & \\
\hline 10. Constraints & 2.74 & 1.29 & -.31 & -.21 & -.28 & -.32 & -.21 & -.31 & -.25 & -.42 & -.40 & - \\
\hline
\end{tabular}

Note. All correlations significant at $p<.001$.

main-relevant variables and their corresponding domain-control measures (see Table 3 ). ${ }^{3}$

Table 3 shows the correlations of the domain-related measures and the domain-specific control measures. The correlations

Table 2

Relationships of Generalized Control and Domain-Related Variables

\begin{tabular}{|c|c|c|c|}
\hline \multirow[b]{2}{*}{ Domain-related variable } & \multicolumn{3}{|c|}{ Control dimension } \\
\hline & Mastery & Constraints & $\begin{array}{l}\text { Life } \\
\text { overall }\end{array}$ \\
\hline \multicolumn{4}{|l|}{ Health domain } \\
\hline Chronic & -.15 & .27 & -.16 \\
\hline Acute & -.18 & .36 & -.24 \\
\hline Functional limitations & -.15 & .30 & -.18 \\
\hline Risk of heart attack & -.09 & .17 & -.10 \\
\hline Risk of cancer & -.07 & .09 & -.09 \\
\hline Do things & .17 & -.19 & .13 \\
\hline Access to medical care & -.06 & .23 & -.13 \\
\hline \multicolumn{4}{|l|}{ Work domain } \\
\hline Keep job & .14 & -.18 & .18 \\
\hline Demands & -.04 & .13 & -.13 \\
\hline Skill & .22 & -.21 & .17 \\
\hline Authority & .18 & -.23 & .22 \\
\hline Coworker support & .09 & -.20 & .14 \\
\hline Supervisor support & .11 & -.16 & .18 \\
\hline \multicolumn{4}{|l|}{ Finances domain } \\
\hline Not enough money & -.13 & .27 & -.25 \\
\hline Difficulty paying bills & -.14 & .31 & -.32 \\
\hline Income & .05 & -.19 & .10 \\
\hline \multicolumn{4}{|l|}{ Contributions domain } \\
\hline Generativity & .26 & -.23 & .18 \\
\hline \multicolumn{4}{|l|}{$\begin{array}{l}\text { Relationship with children } \\
\text { domain }\end{array}$} \\
\hline Child stress & -.07 & .13 & -.08 \\
\hline Contribute to child & .20 & -.37 & .31 \\
\hline \multicolumn{4}{|l|}{ Marriage relationship domain } \\
\hline Separate from spouse & -.08 & .20 & -.32 \\
\hline Spouse stress & -.04 & .12 & -.17 \\
\hline Spouse support & .20 & -.26 & .36 \\
\hline Spouse strain & -.16 & .29 & -.35 \\
\hline \multicolumn{4}{|l|}{ Sex life domain } \\
\hline Frequency of sex & .14 & -.17 & .12 \\
\hline
\end{tabular}

Note. Correlations of .05 or higher are significant at $p<.01$. ranged from .01 to .61 . With a few exceptions, the convergent correlations (i.e., between the control measure and relevant variables for the corresponding domain), which are presented in boldface type, were higher than the discriminant validity correlations (i.e., between a given domain-control measure and variables from non-relevant domains). For example, in the health domain, the correlation of chronic health problems and control over one's health is -.34 , as shown in column one. Correlations between chronic health and the other 6 domain-specific measures ranged from .07 to .19 . In the work domain, the correlation between likelihood of keeping one's job and control over work was .27. Correlations between likelihood of keeping one's job and generalized control ranged from .14 to .18 and with control in other domains ranged from .05 to .15 .

In earlier work (Lachman, 1986; Lachman, Baltes, Nesselroade, \& Willis, 1982) we demonstrated that domain-specific measures accounted for additional variance in domain-relevant outcomes over and above generalized measures of control and showed significantly greater relationships with domain-relevant outcomes than generalized measures. We were able to replicate this pattern with this data set. We conducted multiple regression analyses with the domain-relevant outcomes as dependent variables. To minimize the number of regression analyses, in domains where there were more than two outcomes, we selected the two measures with the highest and lowest correlations with the domain-control measure and conducted regressions to determine whether the same pattern would hold for both variables. The regression equation included the three generalized and six other domain-control measures at the first step. At the second step we added the domain-relevant control measure. In all cases, at the second step, the domain-relevant control measure resulted in a significant change in $R^{2}$, and the beta for the domainspecific measure was the highest in magnitude and was significant at the .001 level (see Table 4).

\section{Sociodemographic Differences}

To examine age differences in control ratings, we divided participants into three age groups. The younger adult group

\footnotetext{
${ }^{3}$ We did not test the differences between all correlations because demonstrating discriminant validity was not a focus of this article. The major purpose of reporting these correlations was to examine whether
} 
Table 3

Relationships of Domain-Specific Control and Domain-Related Variables

\begin{tabular}{|c|c|c|c|c|c|c|c|}
\hline \multirow[b]{2}{*}{ Domain-related variable } & \multicolumn{7}{|c|}{ Control dimension } \\
\hline & Health & Work & Finances & Contributions & $\begin{array}{l}\text { Relationship } \\
\text { with } \\
\text { children }\end{array}$ & $\begin{array}{l}\text { Marriage } \\
\text { relationship }\end{array}$ & $\begin{array}{l}\text { Sex } \\
\text { life }\end{array}$ \\
\hline \multicolumn{8}{|l|}{ Health domain } \\
\hline Chronic & -.34 & -.19 & -.12 & -.11 & -.14 & -.07 & -.13 \\
\hline Acute & -.32 & -.24 & -.21 & -.13 & -.08 & -.13 & -.10 \\
\hline Functional limitations & -.35 & -.21 & -.17 & -.15 & -.11 & -.09 & -.12 \\
\hline Risk of heart attack & -.22 & -.11 & -.10 & -.06 & -.02 & $-.05^{b}$ & -.08 \\
\hline Risk of cancer & -.11 & -.08 & -.07 & -.03 & -.03 & -.08 & -.03 \\
\hline Do things & .22 & .11 & .08 & .10 & .04 & .03 & .05 \\
\hline Access to medical care & -.15 & -.11 & -.13 & -.10 & -.06 & -.11 & -.02 \\
\hline \multicolumn{8}{|l|}{ Work domain } \\
\hline Keep job & .12 & .27 & .15 & .13 & .05 & .10 & .06 \\
\hline Demands & -.14 & -.20 & -.12 & -.06 & -.11 & -.10 & -.10 \\
\hline Skill & .08 & .26 & .18 & .13 & .01 & .07 & .04 \\
\hline Authority & .08 & .40 & .17 & .16 & $.05^{\mathrm{a}}$ & .13 & .07 \\
\hline Coworker support & .08 & .20 & .10 & .15 & .14 & .10 & .08 \\
\hline Supervisor support & .14 & .27 & .14 & .12 & .13 & .10 & .12 \\
\hline \multicolumn{8}{|l|}{ Finances domain } \\
\hline Not enough money & -.10 & -.24 & -.39 & -.20 & -.00 & -.15 & -.02 \\
\hline Difficulty paying bills & -.18 & -.26 & -.45 & -.19 & -.02 & -.21 & -.05 \\
\hline Income & .07 & .13 & .19 & .11 & -.03 & .07 & -.00 \\
\hline \multicolumn{8}{|l|}{ Contributions domain } \\
\hline Generativity & .11 & .17 & .14 & .28 & .12 & .10 & .16 \\
\hline \multicolumn{8}{|c|}{ Relationship with children domain } \\
\hline Child stress & -.10 & -.05 & -.06 & -.01 & -.19 & -.06 & -.08 \\
\hline Contribute to child & .21 & .21 & .25 & .21 & .32 & .24 & .16 \\
\hline \multicolumn{8}{|l|}{ Marriage relationship domain } \\
\hline Separate from spouse & -.06 & -.18 & -.21 & -.11 & -.04 & -.48 & -.21 \\
\hline Spouse stress & -.07 & -.10 & -.16 & -.04 & .00 & -.30 & -.13 \\
\hline Spouse support & .12 & .17 & .22 & .10 & .08 & .61 & .32 \\
\hline Spouse strain & -.12 & -.16 & -.23 & -.12 & -.10 & -.50 & -.31 \\
\hline \multicolumn{8}{|l|}{ Sex life domain } \\
\hline Frequency of sex & .09 & .07 & .05 & .02 & .15 & .18 & .32 \\
\hline
\end{tabular}

Note. Correlations of .05 or higher are significant at $p<.01$. Numerals in boldface type are convergent correlations.

${ }^{\mathrm{n}} n s . \quad{ }^{\mathrm{b}} \mathrm{p}<.05$.

included participants from ages 25 to 39 years, the middle-aged group ranged from age 40 to 59 , and the older adult group ranged from age 60 to 75 . To examine education differences in control, four education groups were created. One group included participants who had less than a high school diploma, a second group included participants who had a high school diploma or who had earned a G.E.D., a third group consisted of participants who had completed a vocational or technical degree or who had completed some college but had not earned a baccalaureate degree, and the fourth group consisted of participants who had earned a baccalaureate degree or who had completed schooling beyond the baccalaureate degree. Table 5 shows the main effect means and standard deviations by age group, by gender, and by education for all of the control measures.

\section{Domain-Control Beliefs}

For five of the control measures (control over health, finances, work, contributions to others, and sex life), we conducted a 3

the one-item domain-control items would show significant relationships with outcomes in the corresponding domain. (age) $\times 2$ (gender) $\times 4$ (education) multivariate analysis of variance (MANOVA). ${ }^{4}$ For two of the domains, control over relationship with children and control over marriage, two separate 3 (age) $\times 2$ (gender) $\times 4$ (education) univariate analyses of variance (ANOVAs) were conducted. Because only a subset of the entire sample responded to those two items (i.e., individuals who had children, were married, or both), those domains were not included in the multivariate analysis of the control

\footnotetext{
${ }^{4}$ We compared the results using MANOVA and multiple regressions controlling for education, sex, and age. Note that the MANOVA approach also controls for each of the independent variables when estimating effects because we used unique sums of squares. The results were the same with a few exceptions. Two additional effects were found with the regression analyses, and one of the effects found with the MANOVA was not significant in the regression. We attribute the few differences between the MANOVA and regression results to two factors: (a) the sample sizes were slightly different because of listwise deletion in the MANOVAs and (b) in the MANOVA we used categorical variables (e.g., 3 age groups, 4 education groups) rather than the continuous variables used in the regressions. We preferred to report the MANOVA results because it required fewer analyses, that is, 3 rather than 10 .
} 
Table 4

Summary of $R^{2}$ Change From Regressions on

Domain-Related Variables

\begin{tabular}{|c|c|c|}
\hline \multirow[b]{2}{*}{ Domain-related variables } & \multicolumn{2}{|c|}{$R^{2}$ change } \\
\hline & Step 1 & Step 2 \\
\hline \multicolumn{3}{|l|}{ Health domain } \\
\hline Risk of cancer & .02 & .01 \\
\hline Functional limitations & .10 & .06 \\
\hline \multicolumn{3}{|l|}{ Work domain } \\
\hline Demands & .05 & .02 \\
\hline Authority & .11 & .09 \\
\hline \multicolumn{3}{|l|}{ Finances domain } \\
\hline Income & .06 & .02 \\
\hline Difficulty paying bills & .17 & .08 \\
\hline \multicolumn{3}{|l|}{ Contributions domain } \\
\hline Generativity & .11 & .04 \\
\hline \multicolumn{3}{|c|}{ Relationship with children domain } \\
\hline Child stress & .04 & .04 \\
\hline Contribute to child & .17 & .05 \\
\hline \multicolumn{3}{|l|}{ Marriage relationship domain } \\
\hline Spouse stress & .11 & .04 \\
\hline Spouse support & .19 & .20 \\
\hline \multicolumn{3}{|l|}{ Sex life domain } \\
\hline Frequency of sex & .06 & .19 \\
\hline
\end{tabular}

Note. The $F$ test of change was significant at $p<.001$ for all domainrelevant variables at Steps 1 and 2 .

measures to minimize missing data. For the MANOVA, followup univariate tests were examined if the multivariate $F s$ were significant. For all significant univariate effects, post hoc comparisons using the Tukey-Kramer (Kirk, 1982) modification of Tukey's HSD test for unequal cell sizes were performed to examine which means differed significantly from each other.

The MANOVA on the five domain-specific measures of control resulted in significant main effects of age, multivariate $F(10$, $5514)=17.63, p<.001$; gender, multivariate $F(5,2757)=$ $7.53, p<.001$; and education, multivariate $F(15,7611)=4.00$, $p<.001$. There were no significant interactions.

Univariate analyses revealed significant age differences in control over work, $F(2,2761)=18.88, p<.001, M S E=6.85$; finances, $F(2,2761) 16.38, p<.001, M S E=6.16$; and sex life, $F(2,2761)=35.84, p<.001, M S E=8.57$. Age differences were also evident in the separate ANOVAs on control over children, $F(2,2412)=46.53, p<.001, M S E=5.82$; and control over marriage $F(2,2090)=5.18, p<.006, M S E=$ 4.55. There were no significant age differences for control over health.

Post hoc comparisons confirmed the following age differences (see Figure 1). For two domains (children, sex), there were decreases in control by age. For control over relationship with children and control over one's sex life, younger adults had greater control than middle-aged or older adults, and middleaged adults had higher control than older adults. Control increased by age for work, finances, and marriage. For control over work and marriage, older adults reported higher control than either younger or middle-aged adults, but there was no difference between middle-aged and younger adults. For financial control, older adults reported higher control than middle- aged or younger adults, and middle-aged adults reported higher control than younger adults.

For gender, there was a significant univariate $F$ for control over sex life, $F(1,2761)=24.60, p<.001, M S E=8.57$. There was also a significant main effect of gender in the ANOVA on control over marriage, $F(1,2090)=25.96, p<.001, M S E$ $=4.55$. Men $(M=6.39)$ felt they had less control over their sex life than women $(M=6.95)$, but more control $(M=7.98)$ over their marriage than women $(M=7.61)$.

The univariate $F$ s for education reached significance for control over health, $F(3,2761)=6.26, p<.001, M S E=3.51$; work, $F(3,2761)=7.11, p<.001, M S E=6.85$; finances, $F(3,2761)=4.99, p<.002, M S E=6.16$; and contributions to others, $F(3,2761)=12.59, M S E=6.18$. Overall, control was higher for respondents with more education (see Figure 2). Post hoc comparisons revealed that for health control, respondents with less than a high school education had lower control than the other three groups, and respondents who had completed some college had lower health control than respondents who had a baccalaureate degree. No other groups differed from each other. For control over work and control over finances, respondents with a baccalaureate degree reported higher control than respondents who had completed some college or those who had less than a high school education. No other means differed. For control over contributions to others, respondents with a baccalaureate degree reported higher control than each of the other three groups, and respondents who had completed some college had higher control than those who had not completed high school.

\section{General Control}

A MANOVA was performed on the general sense of control measures (personal mastery, perceived constraints, and life overall). As in the domain-specific control MANOVA, univariate effects were examined for significant $F_{\mathrm{S}}$ and post hoc analyses using the Tukey-Kramer test were performed to determine which means differed. The MANOVA yielded significant main effects of age, multivariate $F(6,5856)=9.86, p<.001$; gender, multivariate $F(2,2928)=9.03, p<.001$; and education, multivariate $F(9,7126)=18.35, p<.001$. There were no significant interactions.

The univariate ANOVAs revealed significant age differences for constraints, $F(2,2930)=3.06, p<.05, M S E=1.54$; and life overall, $F(2,2930)=12.93, p<.001, M S E=3.51$. Post hoc analyses indicated that older adults scored higher on personal constraints than middle-aged or younger adults. For control over life overall, older adults reported significantly more control than younger or middle-aged adults (see Figure 3 ).

For gender, the univariate ANOVAs were significant for mastery and constraints. For mastery, $F(1,2930)=16.88, p<$ $.001, M S E=1.04$, men $(M=5.94)$ reported higher personal mastery than women $(M=5.74)$. Whereas for perceived constraints, $F(1,2930)=19.33, p<.001, M S E=1.54$, women $(M=2.85)$ reported greater perceived constraints than men $(M$ $=2.60)$.

For education, the univariate ANOVAs were significant for mastery, $F(3,2930)=3.12, p<.03, M S E=1.04$; and perceived constraints, $F(3,2930)=42.88, p<.001, M S E=1.54$; 
Table 5

Means and Standard Deviations for Control Dimensions by Age Group, Gender, and Education

\begin{tabular}{|c|c|c|c|c|c|c|c|c|c|}
\hline \multirow[b]{2}{*}{ Control dimension } & \multicolumn{3}{|c|}{ Age group } & \multicolumn{2}{|c|}{ Gender } & \multicolumn{4}{|c|}{ Education } \\
\hline & Younger & Middle & Older & Men & Women & $<\mathrm{HS}$ & HS & Some college & BA \\
\hline \multicolumn{10}{|l|}{ Finances } \\
\hline$M$ & 6.29 & 6.64 & 7.08 & 6.70 & 6.51 & 6.35 & 6.65 & 6.41 & 6.83 \\
\hline$S D$ & 2.49 & 2.40 & 2.67 & 2.38 & 2.60 & 3.02 & 2.46 & 2.52 & 2.32 \\
\hline \multicolumn{10}{|l|}{ Sex } \\
\hline$M$ & 7.21 & 6.68 & 5.67 & 6.39 & 6.95 & 6.35 & 6.79 & 6.69 & 6.65 \\
\hline$S D$ & 2.51 & 2.92 & 3.63 & 2.84 & 3.10 & 3.50 & 2.99 & 3.07 & 2.70 \\
\hline \multicolumn{10}{|l|}{ Contributions } \\
\hline$M$ & 6.94 & 7.15 & 7.08 & 6.99 & 7.14 & 6.53 & 6.89 & 6.98 & 7.48 \\
\hline$S D$ & 2.47 & 2.43 & 2.79 & 2.55 & 2.48 & 2.98 & 2.60 & 2.54 & 2.17 \\
\hline \multicolumn{10}{|l|}{ Work } \\
\hline$M$ & 6.94 & 6.90 & 7.72 & 7.11 & 7.02 & 6.60 & 7.07 & 6.90 & 7.38 \\
\hline$S D$ & 2.38 & 2.71 & 2.91 & 2.61 & 2.70 & 3.24 & 2.77 & 2.66 & 2.28 \\
\hline \multicolumn{10}{|l|}{ Child } \\
\hline$M$ & 8.44 & 7.44 & 6.93 & 7.52 & 7.65 & 7.48 & 7.76 & 7.45 & 7.60 \\
\hline$S D$ & 1.86 & 2.39 & 2.98 & 2.46 & 2.49 & 2.82 & 2.47 & 2.60 & 2.17 \\
\hline \multicolumn{10}{|l|}{ Health } \\
\hline$M$ & 7.81 & 7.58 & 7.53 & 7.69 & 7.61 & 7.18 & 7.67 & 7.59 & 7.84 \\
\hline$S D$ & 1.86 & 1.88 & 1.91 & 1.74 & 2.01 & 2.35 & 1.90 & 1.96 & 1.58 \\
\hline \multicolumn{10}{|l|}{ Marriage } \\
\hline$M$ & 7.66 & 7.78 & 8.11 & 7.98 & 7.61 & 7.76 & 7.90 & 7.66 & 7.87 \\
\hline$S D$ & 2.16 & 2.14 & 2.13 & 1.96 & 2.33 & 2.49 & 2.10 & 2.26 & 1.96 \\
\hline \multicolumn{10}{|l|}{ Life } \\
\hline$M$ & 7.68 & 7.75 & 8.16 & 7.84 & 7.79 & 7.74 & 7.92 & 7.69 & 7.87 \\
\hline$S D$ & 1.78 & 1.91 & 1.94 & 1.75 & 2.00 & 2.28 & 1.94 & 1.91 & 1.64 \\
\hline \multicolumn{10}{|l|}{ Mastery } \\
\hline$M$ & 5.93 & 5.81 & 5.75 & 5.94 & 5.74 & 5.73 & 5.85 & 5.78 & 5.92 \\
\hline$S D$ & .89 & 1.08 & 1.08 & .94 & 1.09 & 1.16 & 1.00 & 1.07 & .94 \\
\hline \multicolumn{10}{|l|}{ Constraints } \\
\hline$M$ & 2.62 & 2.72 & 2.93 & 2.60 & 2.85 & 3.43 & 2.89 & 2.72 & 2.36 \\
\hline$S D$ & 1.13 & 1.31 & 1.43 & 1.22 & 1.33 & 1.57 & 1.29 & 1.24 & 1.07 \\
\hline
\end{tabular}

Note. Younger $=25-39$ years; middle $=40-59$ years; older $=60-75$ years; $<\mathrm{HS}=$ did not complete high school; HS $=$ received a high school diploma or G.E.D. certificate; some college $=$ completed a vocational, associate's, or a 2-year college degree or attended, but did not complete, a 4-year degree program; $\mathrm{BA}=$ received a bachelor of arts degree.

but not for life overall ( see Figure 4). Post hoc tests showed that for mastery, respondents with a baccalaureate degree or higher had higher mastery than respondents with less than a high school education and higher mastery than respondents who had attended some college but who did not have a baccalaureate degree. None of the other means differed significantly from each other. For perceived constraints, the means for each of the four education groups differed significantly from the other means. Perceived constraints decreased with increases in educational attainment.

\section{Discussion}

The results showed that adults had a differentiated view of control in that there were variations across domains. In general, adults felt the least control over their sex life and their finances and the most control over their marriage and life overall. Consistent with past work there were no age differences in a general sense of mastery, but there were increases in beliefs about external constraints (Lachman, 1986). For their life overall, older adults reported greater control than the younger and middle- aged adults. It is interesting to note that although older adults reported the highest level of control for life overall, they also indicated they faced more constraints than the other age groups. Thus, in the context of greater constraints, the older adults in this sample were able to find a means for maintaining a high sense of control over their lives, even though in some domains control was lower than for the younger age groups.

For the specific domains examined, control beliefs were higher for work, finances, and marriage and lower for children and sex life, with age. Middle-aged adults did not differ from younger adults for control over work, marriage, and life overall; however, they reported less control over their relationship with children and sex life. The only domain in which middle-aged adults had higher control than younger adults was for finances. Thus, there was no evidence to support the view that midlife is the peak age period for sense of control in any of the domains, as suggested in earlier work (Lachman, Lewkowicz, et al., 1994; Mirowsky, 1995; Neugarten, 1968). For the domains that showed age-related increases in control, the middle-aged looked more like the younger adults than the older adults, with the exception of finances, for which they differed from both younger 

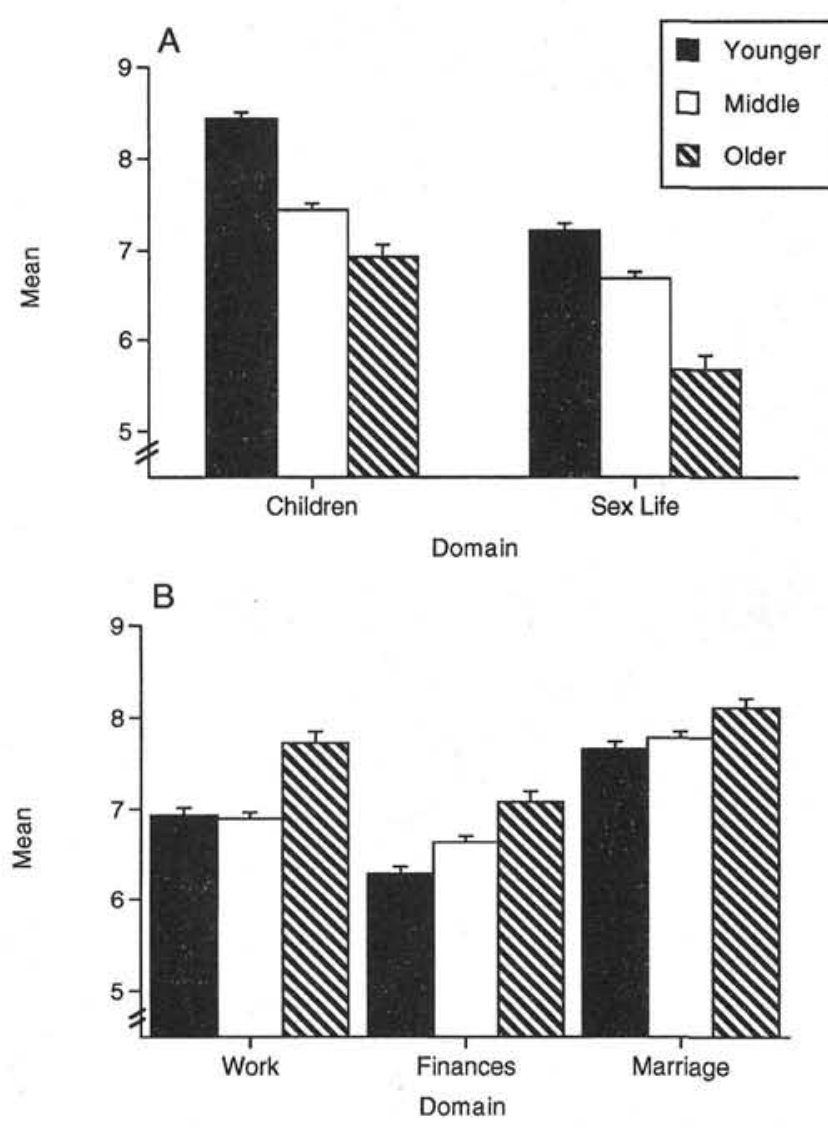

Figure 1. Age differences in control domains.

and older adults. For the relationship with children and sex life domains, which showed decreases over the adult age span, the middle-aged had lower control than the younger adults, but higher control than the older adults.

For health, all age groups had relatively strong beliefs in control, but they did not vary by age. This may be indicative of the widespread attention given to taking control over one's health portrayed in the media. In past work, control over health was found to decrease with age (Lachman, 1986, 1991). In the earlier studies, however, the older adults included those over 75 years of age, and the decreases in control may have been primarily for the old-old, who were not included in our study. There was a slight trend toward a decrease in health control, but it may not be a significant change until after age 75 . Those who rated their health control higher were healthier and had fewer functional limitations.

Given the cross-sectional nature of the study, the usual caveats must be acknowledged (Baltes, Cornelius, \& Nesselroade, 1979). First, it is possible that these differences reflect cohort variations or generational differences rather than true age-developmental increases or decreases. Another alternative interpretation is that the differences reflect selection effects. For example, control over marriage may appear to increase with age because those who felt they had little control over their marriages may no longer be married in later life and therefore were not included in the analysis for this domain. Indeed, older adults rated their marriage as less likely to end in separation or divorce than the younger or middle-aged groups. For work, it is possible that those who are no longer working feel a greater sense of control over work than those who are working. The main analysis included all working and nonworking participants. We examined whether the age incremental pattern for work control could be because older adults are less likely to be in the labor force (39\% working compared to $85 \%$ of younger adults and $83 \%$ of middleaged adults). We conducted the same analysis selecting only those who were currently employed and found the identical pattern (i.e., older adult workers [ $M=7.97]$ had significantly higher work control beliefs relative to younger $[M=7.00]$ ) and middle-aged adults [ $M=7.04]$ ).

More education was associated with greater control over health, work, finances, and making a contribution to the welfare of others. These differences in control by education were consistent across the age groups. It is not possible to determine whether education leads to a greater sense of control because of more opportunities and resources or whether those who have a greater sense of control were the ones more likely to seek advanced education. Those who have higher control beliefs should be more motivated to pursue higher education because they believe they are able to bring about desired outcomes and education is one means to facilitate this. It is also possible that education is a marker for socioeconomic status. Indeed, those participants with higher education were found to have higher levels of total household income $(r=.33)$. In past research, the sense of control has been found to vary by income level (Lachman \& Weaver, 1998).

In past work, few significant gender differences in control have been identified. In a meta-analysis of differences in control beliefs, Feingold (1994) found no gender differences. However, the trend across most studies was for men to show higher control beliefs than women. The majority of the studies analyzed used

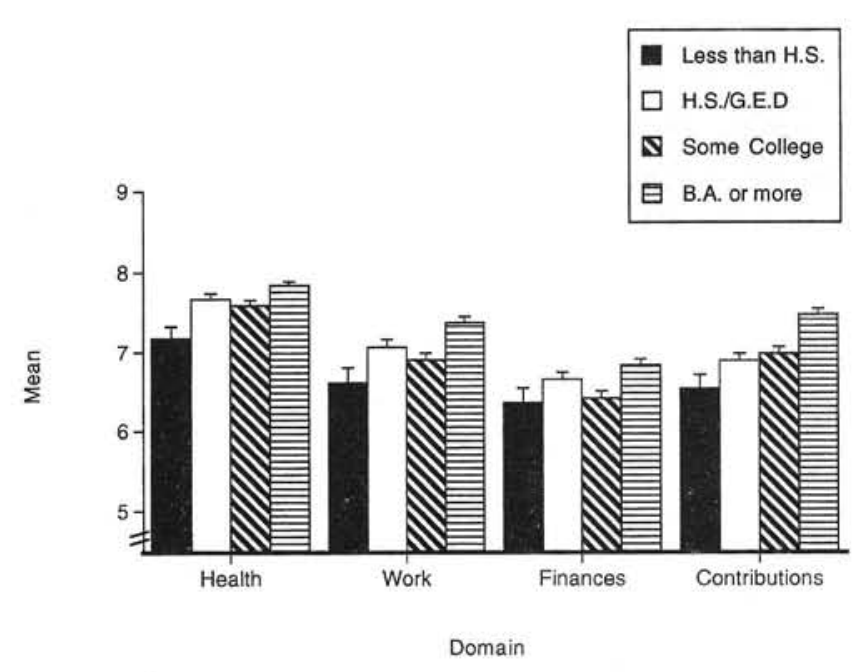

Figure 2. Education differences in control domains. H.S, = received a high school diploma; G.E.D. = high school equivalency diploma; Some college = completed a vocational, associate's, or a 2-year college degree or attended, but did not complete, a 4-year degree program; B.A. = bachelor of arts degree. 
A

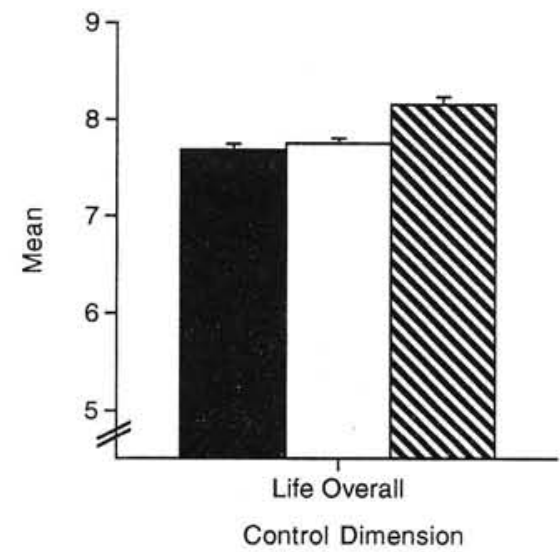

B

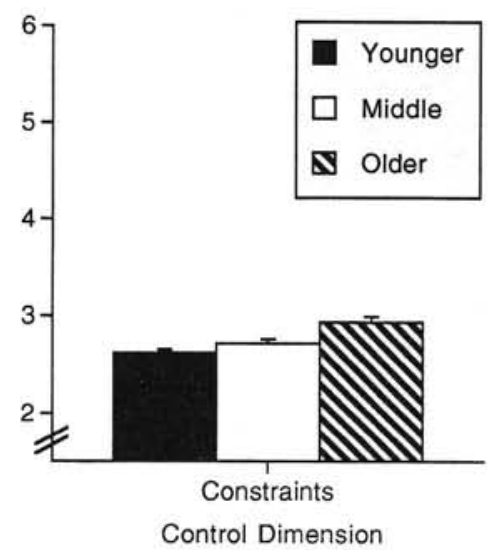

Figure 3. Age differences in generalized control.

generalized measures of control. In our study, men had higher general control, with higher mastery and lower perceived constraints. Gender differences in control were also found for two domains, marriage and sex life. The fact that women were found to have a higher sense of control than were men for the sex life domain is interesting given that when sex differences are found, it is typically men who have a higher sense of control than women. These results are consistent with the popular view that women are the ones who regulate sexual activity in a relationship (e.g., "Not now honey, I have a headache.").

Beliefs about control in different domains were related to a variety of domain-related circumstances and experiences. Those who had a greater sense of control over their marriage were less likely to expect their marriage would end in separation and

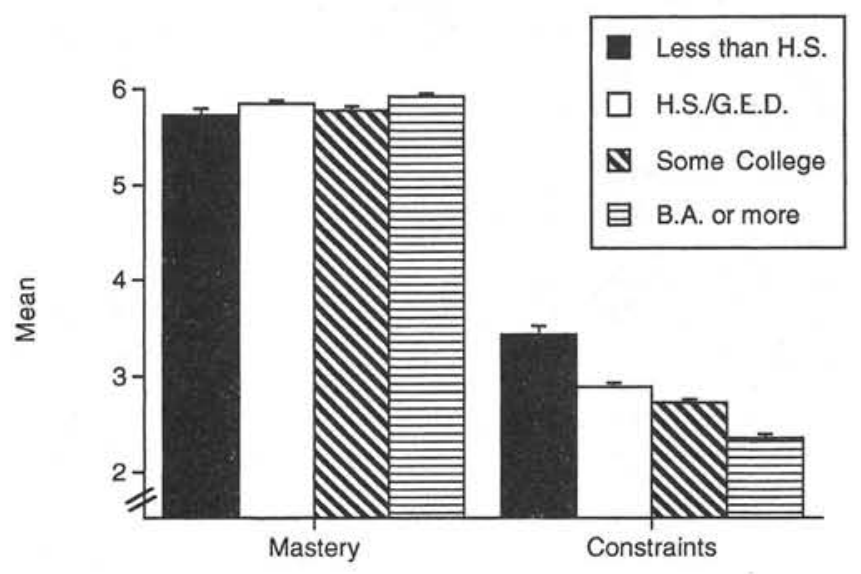

Control Dimension

Figure 4. Education differences in generalized control. H.S. = received a high school diploma; G.E.D. = high school equivalency diploma; Some college = completed a vocational, associate's, or a 2-year college degree or attended, but did not complete, a 4-year degree program; B.A. = bachelor of arts degree. experienced less stress and strain, but received a greater amount of support from their spouse. Those who had a greater sense of control over their sex life reported engaging in sexual relations more often. For health control, those who had greater control had better health, saw their risks for heart disease and cancer as lower, had better access to medical care, and were more likely to believe there are things one can do to stay healthy. Those who felt they were in control of their work were more likely to think they would be able to keep their job and felt greater control over several aspects of their work environment. Control over finances was related to higher income as well as to having adequate money to pay bills. Those who were more in control of making a contribution to others showed higher levels of generativity. And those who had greater control over their relationship with their children reported less stress with their children and a greater ability to help their children. These findings show that beliefs about control in a given domain are a reflection of important experiences within that domain and are associated with adaptive or positive outcomes. Nevertheless, these correlations cannot provide an answer as to the processes involved in developing a sense of control.

Previous work suggests that having resources and positive experiences such as social support is a likely source of a sense of control (McAvay et al., 1996). However, it is also likely that control beliefs facilitate adaptive functioning and help to sustain and enrich one's resources (Lachman, Ziff, \& Spiro, 1994).

The results also highlight the usefulness of domain-specific assessments of control. The domain-specific measures showed stronger relationships with the domain-relevant outcomes than did generalized measures as found in past research (Lachman, 1986). Another reason to use domain-specific measures in addition to or instead of generalized measures is that patterns of age differences may vary across domains. For example, a composite scale of control of partner and children would have provided an internally consistent measure of perceived control over family relationships, but age differences would have been obscured because one of these relationships shows increases and the other shows decreases in control with age. 
One of the challenges of later life is to maintain a sense of control in the midst of the changing balance of gains and losses (Baltes \& Baltes, 1990; Lachman, Ziff, et al., 1994). To the extent that adults can feel in control over key areas of their lives, they have an important psychological resource. These beliefs, along with other factors such as social support, play a protective role in the face of decrements and loss (Rodin, 1986; Rowe \& Kahn, 1987). On the one hand, maintaining a sense of control may help one to prevent or minimize decrements in later life. At the same time, a sense of control may facilitate adaptive responses to declines that are associated with the aging process.

Our findings suggest that adults believe they have varying amounts of control in different aspects of their lives. The amount of perceived control in key domains of life is related to sociodemographic factors such as age, gender, and education. Control beliefs are also related to key experiences, behaviors, and outcomes. Future work is needed to examine the processes linking these beliefs about control with adaptive functioning in adulthood.

\section{References}

Baltes, P. B., \& Baltes, M. M. (1986). The psychology of control and aging. Hillsdale, NJ: Erlbaum.

Baltes, P. B., \& Baltes, M. M. (1990). Psychological perspectives on successful aging: The model of selective optimization with compensation. In P. B. Baltes \& M. M. Baltes (Eds.), Successful aging: Perspectives from the behavioral sciences (pp. 1-34). New York: Cambridge University Press.

Baltes, P. B., Cornelius, S. W., \& Nesselroade, J. R. (1979). Cohort effects in developmental psychology. In J. R. Nesselroade \& P. B. Baltes (Eds.), Longitudinal research in the study of behavior and development (pp. 61-110). New York: Academic Press

Brändtstadter, J., \& Renner, G. (1990). Tenacious goal pursuit and flexible goal adjustment: Explication and age-related analysis of assimilative and accommodative strategies of coping. Psychology and Aging, $5,58-67$.

Brim, G. (1992). Ambition: How we manage success and failure throughout our lives. New York: Basic Books.

Feingold, A. (1994). Gender differences in personality: A meta-analysis. Psychological Bulletin, 116, 429-456.

Gurin, P., \& Brim, O. G., Jr. (1984). Change in self in adulthood: The example of sense of control. In P. B. Baltes \& O. G. Brim, Jr. (Eds.), Life-span development and behavior (Vol. 6, pp. 281-334). New York: Academic Press.

Kirk, R. E. (1982). Experimental design: Procedures for the behaviaral sciences (2nd ed.). Belmont, CA: Brooks/Cole Publishing.

Lachman, M. E. (1986). Locus of control in aging research: A case for multidimensional and domain-specific assessment. Psychology and Aging, 1, 34-40.

Lachman, M. E. (1991). Perceived control over memory aging: Developmental and intervention perspectives. Joumal of Social Issues, 47, 159-175.

Lachman, M. E., Baltes, P. B., Nesselroade, J. R., \& Willis, S. L. (1982). Examination of personality-ability relationships in the elderly: The role of the contextual (interface) assessment mode. Journal of Research in Personality, 16, 485-501.
Lachman, M. E., Bandura, M., Weaver, S. L., \& Elliott, E. (1995). Assessing memory control beliefs: The memory controllability inventory. Aging \& Cognition, 2, 67-84.

Lachman, M. E., \& James, J. B. (1997). Charting the course of midlife development. In M. E. Lachman \& J. B. James (Eds.), Multiple paths of midlife development (pp. 1-17). Chicago: University of Chicago Press.

Lachman, M. E., Lewkowicz, C., Marcus, A., \& Peng, Y. (1994). Images of midlife development among young, middle-aged, and older adults. Journal of Adult Development, 1, 201-211.

Lachman, M.E., \& Weaver, S. L. (1998). The sense of control as a moderator of social class differences in health and well-being. Journal of Personality and Social Psychology, 74, 763-773.

Lachman, M. E., Ziff, M. A., \& Spiro, R. (1994). Maintaining a sense of control in later life. In R. P. Abeles, H. C. Gift, \& M. G. Ory (Eds.), Aging and quality of life (pp. 216-232). New York: Springer.

Lyons, H. W., \& Lachman, M. E. (1997). Social support and strain from partmer, family and friends: Costs and benefits from men and women. Manuscript submitted for publication.

McAdams, D. P., \& St. Aubin, E. de (1992). A theory of generativity and its assessment through self-report, behavioral acts, and narrative themes in autobiography. Journal of Personality and Social Psychology, 62, 1003-1015.

McAvay, G. J., Seeman, T. E., \& Rodin, J. (1996). A longitudinal study of change in domain-specific self-efficacy among older adults. Journal of Gerontology: Psychological Sciences, 51B, P243-P253.

Mirowsky, J. (1995). Age and the sense of control. Social Psychology Quarterly, 58, 31-43.

Neugarten, B. L. (1968). The awareness of middle age. In B. L. Neugarten (Ed.), Middle age and aging (pp. 93-98). Chicago: University of Chicago Press.

Pearlin, L., \& Schooler, C. (1978). The structure of coping. Journal of Health and Social Behavior, 19, 2-21.

Rodin, J. (1986, September 19). Aging and health: Effects of the sense of control. Science, 233, 1271-1276.

Rowe, J., \& Kahn, R. (1987, July 10). Human aging: Usual and successful. Science, 237, 143-149.

Schulz, R., Heckhausen, J., \& Locher, J. (1991). Adult development, control, and adaptive functioning. Journal of Social Issues, 47, 177196.

Schwartz, J., Pieper, C., \& Karasek, R. A. (1988). A procedure for linking job characteristics to health surveys. American Journal of Public Health, 78, 904-909.

Shannon, L. L. (1994). The effects of role quality and mastery on psychological and physical health. Unpublished doctoral dissertation, Brandeis University.

Skinner, E. A. (1996). A guide to constructs of control. Journal of Personality and Social Psychology, 71, 549-570.

Wallston, K. A., \& Wallston, B. S. (1981). Health related locus of control scales. In H. M. Lefcourt (Ed.), Research with the locus of control construct: Assessment methods (Vol. 1, pp. 189-243). New York: Academic Press.

Wolinsky, F. D., \& Stump, T. E. (1996). Age and the sense of control among older adults. Joumal of Gerontology: Social Sciences, S1B, S217-S220.

Received January 27, 1997

Revision received March 24, 1998

Accepted April 2, 1998 